\title{
Detection of Bovine Rotavirus from Diarrheic Bovine calves in Gujarat region, India
}

\author{
${\text { Jayesh } \text { Patel }^{1}{ }^{*} \text {, Rafiyuddin Mathakiya }}^{2}$ and Akash Golaviya ${ }^{3}$ \\ ${ }^{1}$ Department of Veterinary Microbiology, College of Veterinary Science \& Animal \\ Husbandry, AAU, Anand-388 001, Gujarat, India \\ ${ }^{2}$ Department of Veterinary Microbiology, College of Veterinary Science and A.H., AAU, \\ Anand, India \\ ${ }^{3}$ Department of Veterinary Microbiology, College of Veterinary Science \& A.H., AAU, Anand, \\ India \\ *Corresponding author
}

\section{A B S T R A C T}

Keywords

Neonatal Calf

Diarrhea, Calf

Scour,

Rotavirus,LAT,

ELISA, RT-PCR

Article Info

Accepted:

15 August 2019

Available Online:

10 September 2019
The aim of the current study was to identify the prevalence of bovine rotavirus infection in bovine calves aged from 1 day to 2 months old in Gujarat region. Studied samples were divided into 4 age groups, age group I (1-10 days) age group II 911-20 days), age group III (21-30 days) and age group IV (31-60 days). All the samples were screened by latex agglutination test (LAT), ELISA and RT-PCR technique. Among the 117 fecal sample screened, 23.93\%, $15.38 \%$ and $22.22 \%$ found positive for Rotavirus by LAT, ELISA and RT-PCR respectively. Age wise, rotavirus infection was highly prevalent in age group-I (1-10 days) i.e. $38.46 \%$. Sex wise, there was no clear-cut establishment of correlation for Rotavirus. The present study showed that rotaviruses are involved in the neonatal calves' diarrhea in Gujarat area

\section{Introduction}

Bovine rotavirus is a primary and most common pathogen responsible for the NCD. Rotavirus diarrhea in calves, piglets, foals and lambs is often referred as "white scour" or "milk scour". Bovine rotavirus usually causes diarrhea in calves at 1 to 2 weeks of age
(Dhama et al., 2009). It has been reported that diarrhea in calves from 5-10 days of age is commonly due to rotavirus and infected calves excrete rotavirus in their feces upto the age of 6 to 8 weeks. Rotavirus was first isolated from calves with diarrhea and since then has been isolated from cattle, sheep, horses, dogs, cats, chickens and turkeys (Mebus et al., 1969). 
The disease is usually seen in young animals and the susceptibility to disease decreases as the age progress, most likely due to changes in animal physiology and/or acquired immunity due to previous exposures (Estes and Kapikian, 2007).

The virus belongs to the genus Rotavirus of subfamily Sedoreovirinae in the family Reoviridae. Rotavirus is dsRNA, nonenveloped, 65-75 $\mathrm{nm}$ in diameter, icosahedron symmetry having 11 double-stranded RNA segments (16 21 kb) and is very stable over a wide $\mathrm{pH}$ range with heat stability (MacLachlan et al., 2016). The fully infectious rotavirus particle consists of three protein layers (i.e. core, inner capsid and outer capsid) and is also termed triple-layered particle (TLP). By electron microscopy, TLPs resemble wheels (latin. rota), and this appearance has led to the name of Rotavirus for the genus (Flewett et al., 1974).

The dsRNA segments of Rotavirus code for six structural proteins (SPS) viz. VP7VP4VP6-VP1-VP2-VP3 and six non-structural proteins (NSPs) viz. NSP1-NSP2-NSP3NSP4-NSP5/6. The VP6 protein comprises the middle layer of the capsid and is the protein, encoded by gene segment 6 , to which common immunodiagnostics are directed. Rotavirus has 11 segments of the dsRNA as the genome and that could be detected by RNA-Polyacrylamide Gel Electrophoresis (RNA-PAGE). The eleven segments of the dsRNA are separated from each other based on their electrophoretic mobility and it is very sensitive method for determination of the presence of Rotavirus in fecal samples. The detection of 11 segments of dsRNA of RVA in RNA-PAGE exhibited the 4-2-3-2 pattern of migration.RVA are excreted in large numbers in the feces and can be detected by the various methods viz. Reverse TranscriptasePolymerase Chain Reaction (RT-PCR), Enzyme Linked Immunosorbent Assay
(ELISA), PAGE, Latex agglutination test (LAT), Electron microscopy, Passive hemagglutination assay (PHA), Immunoblotting and Immunofluorescence test.

\section{Materials and Methods}

The present study was undertaken to ascertain detection of bovine rotavirus from fecal samples of diarrheal calves of cattle and buffalo by Enzyme Linked Immunosorbent Assay (ELISA) and Reverse TranscriptasePolymerase Chain Reaction (RT-PCR) techniques.

\section{Collection of specimens}

All the 117 fecal samples were collected from calves of cattle and buffalo of 1 day to 2 months of age. Samples were collected from farms of various region viz. Anand $(n=31)$, Surat $(n=68)$ and Junagadh $(n=18)$. The fecal samples were collected as per the method of Yilmaz (2016). The samples were transferred to sterile disposable plastic specimen vial. The specimen vial was labelled properly according to the species, age, sex and name of owner etc. The sample was stored in deep freeze $\left(-40^{\circ} \mathrm{C}\right)$ for detection of viral antigen until use.

\section{Screening by Latex Agglutination Test (LAT)}

All the fecal samples were screened for rotavirus antigen by LAT(Figure 1). LAT was performed to detect rotavirus antigen in fecal supernatants as per instruction by the kit manufacturer (HiRotavirus Latex Test Kit, LK08, HimediaPvt. Ltd.).

\section{Sample Preparation for ELISA}

The fecal sample was diluted in dilution buffer (provided by kit manufacturer) volume per volume (v/v). This was a qualitative dilution only, which must allow the pipetting the fecal 
suspensions. The gruds were discarded by natural sedimentation for about 10 minutes without centrifugation.

\section{Screening by ELISA}

All the samples again screened rotavirus antigen by ELISA. ELISA was performed to detect bovine rotavirus in the fecal samples by the kit manufacture (Bio $\mathrm{X}$ Diagnostic Multiscreen Ag ELISA kit (BIO K 315/1, Belgique). This 96 well plate ELISA kit also used for diagnosis of Coronavirus and $E$. coli F5 attachment factor from fecal sample of calves along with Rotavirus(Figure 2). The ELISA plate is sensitised with a mixture of antibodies that are specific for the above 3 pathogens. These antibodies capture the corresponding pathogens in the faecal samples. The net optical density of each sample was calculated by following formula: $\operatorname{Val}($ ue $)=\frac{\text { Delta OD Sample }: 100}{\text { Delta OD Positive }}$

The optical density of $\geq 6.0$ at $450 \mathrm{~nm}$ wavelength were considered as positive for Rotavirus by antigen detection sandwich ELISA

\section{Extraction of Viral RNA}

Viral RNA extraction was done from fecal suspensions $(10 \% \mathrm{v} / \mathrm{v})$ by using a QIAamp Viral RNA Mini Kit, QIAGEN (Cat. No. 52904) following the manufactures protocol.

\section{Quality and Quantity Check of RNA}

For quantification of viral RNA, absorbance was read in Nanodrop Spectrophotometer at $260 \mathrm{~nm}$.

An optical density (OD) 1 corresponds to $40 \mu \mathrm{g} / \mathrm{ml}$ for dsRNA. A ratio of 260:280 provides an estimate of purity of the nucleic acid. Pure preparations of RNA have 260:280 ratio of 2.0. The viral RNA from fecal samples was quantified and the ratio of purity was evaluated following the method of Sambrook and Russel (2012).

\section{Molecular Detection of Rotavirus by RT-} PCR

The RT-PCR assay for specific VP6 gene was standardized using the viral genomic RNA extracted by QIAamp RNA Mini Kit, QIAGEN (Cat. No. 52904)(Table 1).

The genomic RNA was quantitated by Nanodrop and used as a template for cDNA synthesis by using components of PrimeScriptTM RT-PCR kit, TaKaRa (Cat. No. RR014A). The reaction conditions for RT-PCR using PrimeScriptTM RT-PCR kit, TaKaRa were standardized to get the desired specific product. The reaction mixture of polymerase chain reaction (PCR)as per Table 2 and thermo cycling conditions used for PCR to amplify full-length VP6 gene as per Table.3.

\section{Visualization of PCR products by agarose gel electrophoresis}

To confirm the targeted PCR amplification, $5 \mu 1$ of the PCR products from each tube was mixed with $1 \mu \mathrm{l}$ of $6 \mathrm{X}$ gel loading buffer and electrophoresed along with DNA molecular weight marker (HiMediaPvt. Ltd) on $2.0 \%$ agarose (Low EEO, SeaKem) gels containing $0.5 \mu \mathrm{g} / \mathrm{ml}$ ethidium bromide (Sigma-Aldrich, USA) at $80 \mathrm{~V}$ in $0.5 \mathrm{X}$ Tris Borate EDTA (TBE) buffer. The amplified product was visualized as single compact band of expected size under UV light and documented by gel documentation system (Genetix Biotech Pvt. Ltd, Delhi).

\section{Results and Discussion}

A total 117 fecal samples were collected from diarrheic calves from farms of various region 
viz. Anand, Surat and Junagadh, and screened for the presence of Rotavirus using latex agglutination test (LAT), ELISA and RTPCR.

Out of 117 diarrheic samples screened for Rotavirus, 28 (23.93\%), 18 (15.38\%) and 26 (22.22\%) samples were found positive for Rotavirus by LAT, ELISA and RT-PCR method, respectively as mentioned in Table 4 . The results of RT-PCR were taken in to consideration to show the prevalence of Rotavirus. The RT-PCR technique is widely used for the detection of the RNA viruses. It helps in the detection of viral nucleic acid during initial stages of infection without waiting for higher virus titre and development of immune response in the affected host species. The amplification of fragment of VP6 gene of Bovine rotavirus in RT-PCR indicated that calves were suffering from rotaviral infection (Figure 3).In the present study, overall prevalence of Rotavirus recorded was almost similar to Suresh et al., (2012), Abdulazeez et al., (2017), and Pardo-Mora (2018) they observed $24.10 \%, 25.60 \%$ and $19.70 \%$, respectively. In contrast to present study, Mondal et al., (2013), Yilmaz (2016) andGill et al., (2017) observed low prevalence of Rotavirus i.e. $11.23 \%, 7.57 \%$ and $10 \%$, respectively.

The difference in Rotavirus prevalence in diarrheic calves which established in the present study and by above mentioned investigators is in agreement due to scientific fact that rotaviruses area worldwide distributed and able to infect humans and domesticated animals. Various factors like hygienic measures, proper access to maternal colostrum, nutrition season and climatic factors such as rainfall, temperature, relative humidity etc. might be responsible for rotaviral diarrhea as reported by Abdulazeez et al., (2017). Negative results may occur because some cases of diarrhea might not be associated with infectious agents, and probably due to nutritional or other management factors, or because other noninvestigated pathogens might be involved as reported by Ammar et al., (2014).

Out of 117 fecal samples, 28 (23.93\%) samples were found positive for Rotavirus by latex agglutination test as indicated in the form of clump/agglutination of latex particles in the test sample and positive control, and absence of agglutination in negative control (Figure 4). AlYousif et al., (2001) and Singh (2011) reported higher $52 \%$ and $32.07 \%$ prevalence of rotavirus infection whereas Sukura et al., (1990) reported lower (12\%) prevalence of Rotavirus by LAT.

In the present investigation, 18 (15.38\%) samples were found positive by ELISA(Figure $5)$. The result is in agreement with Al-Robaiee and Al-Farwachi (2013), Ammar et al., (2014) and Singh et al., (2015), as they reported $15.50 \%, 14.63$ and $12 \%$ prevalence of Rotavirus.

In contrast to present study, Wei et al., (2013), Khamees et al., (2015) and Abdulazeez et al., (2017) reported42.05\%, $43.50 \%$ and $36 \%$ prevalence of Rotavirus.

\section{Region wise Prevalence of Rotavirus}

Rotavirus was highly prevalent in Junagadh $(38.88 \%)$ as compared to Anand $(22.58 \%)$ and Surat $(17.64 \%)$ region. This high and low prevalence in various regions might be due to the difference in climatic conditions, sample size, management practices, personal hygiene, the age at which sample was collected and farm size (Table 5).

\section{Age and Sex wise Prevalence of Rotavirus}

In the present study, the association between the different age groups and sex with the 
occurrence of diarrhea due to Rotavirus was studied (Table 6). The rotavirus infection (38.46\%) highly 60 days. prevalent in 1-10 days of age group of calves followed by $30.76 \%, 19.23 \%$ and $11.53 \%$ for age group of 11-20 days, 21-30 days and 31-

Table.1 Oligonucleotide primer (VP6) sequence used in RT-PCR of $B R V$

\begin{tabular}{|c|c|c|c|}
\hline Primers & Sequences (5'-3') & $\begin{array}{c}\text { Expected } \\
\text { product } \\
\text { size (bp) }\end{array}$ & Reference \\
\hline VP6 F & GACGGVGCRACTACATGGT (19) & $\mathbf{3 7 9}$ & Yilmaz, 2016 \\
\hline VP6 R & GTCCAATTCATNCCTGGTGG (20) & & \\
\hline
\end{tabular}

Table.2 Reaction of polymerase chain reaction (PCR)

\begin{tabular}{|c|c|}
\hline Reagents & Volume $(\boldsymbol{\mu l})$ \\
\hline 10 X PCR Buffer II & 5 \\
\hline dNTP Mixture $(\mathbf{1 0} \mathbf{M m}$ each) & 2 \\
\hline VP6 F $(\mathbf{2 0} \boldsymbol{\mu M})$ & 10 \\
\hline VP6 R $(\mathbf{2 0} \boldsymbol{\mu M})$ & 10 \\
\hline TaKaRa Ex Taq $\mathbf{H S}(\mathbf{5} \mathrm{U} / \boldsymbol{\mu l})$ & 0.5 \\
\hline cDNA & 5 \\
\hline Sterile water & 17.5 \\
\hline Total & 50 \\
\hline
\end{tabular}

Table.3 Thermo cycling conditions used for PCR to amplify full-length VP6 gene

\begin{tabular}{|c|c|c|c|c|}
\hline Sr. No. & Step & Temperature & Time & 40 \\
\hline 1 & Denaturation & $94^{\circ} \mathrm{C}$ & 30 seconds & Cycles \\
\hline 2 & Annealing & $55^{\circ} \mathrm{C}$ & 30 seconds & \\
\hline 3 & Extension & $72^{\circ} \mathrm{C}$ & 90 seconds & \\
\hline
\end{tabular}

Table.4 Detail information of Rotavirus positive samples by various methods

\begin{tabular}{|c|c|c|c|c|c|c|}
\hline \multirow{2}{*}{ Sr. No. } & \multirow{2}{*}{ Sample code } & \multicolumn{2}{|c|}{ Bovine Calf } & \multirow{2}{*}{ LAT } & \multirow{2}{*}{ ELISA } & RT-PCR \\
\cline { 3 - 5 } & $\begin{array}{c}\text { Age } \\
\text { (Days) }\end{array}$ & $\begin{array}{c}\text { Sex } \\
\end{array}$ & & & \\
\hline $\mathbf{1}$ & A-8 & 15 & Female & ++++ & ++++ & Positive \\
\hline $\mathbf{2}$ & A-9 & $\mathbf{3}$ & Female & - & ++ & Negative \\
\hline $\mathbf{3}$ & A-10 & $\mathbf{2 7}$ & Female & ++ & - & Positive \\
\hline $\mathbf{4}$ & A-11 & 45 & Male & ++++ & +++ & Positive \\
\hline $\mathbf{5}$ & A-17 & $\mathbf{2 0}$ & Male & + & - & Positive \\
\hline $\mathbf{6}$ & A-18 & $\mathbf{7}$ & Female & ++ & - & Positive \\
\hline $\mathbf{7}$ & A-30 & 30 & Male & + & ++ & Positive \\
\hline $\mathbf{8}$ & A-31 & 7 & Male & ++ & ++ & Positive \\
\hline
\end{tabular}




\begin{tabular}{|c|c|c|c|c|c|c|}
\hline 9 & S-34 & 45 & Female & +++ & - & Positive \\
\hline 10 & S-35 & 30 & Female & + & - & Positive \\
\hline 11 & S-43 & 8 & Male & +++ & ++ & Positive \\
\hline 12 & S-49 & 11 & Male & ++++ & ++ & Positive \\
\hline 13 & S-50 & 7 & Male & ++ & - & Negative \\
\hline 14 & S-55 & 6 & Male & ++++ & +++ & Positive \\
\hline 15 & S-56 & 11 & Male & ++++ & +++ & Positive \\
\hline 16 & S-75 & 2 & Male & +++ & +++ & Positive \\
\hline 17 & S-76 & 25 & Male & ++ & - & Negative \\
\hline 18 & S-84 & 1 & Female & +++ & +++ & Positive \\
\hline 19 & S-86 & 1 & Female & +++ & +++ & Positive \\
\hline 20 & S- 88 & 2 & Female & +++ & +++ & Positive \\
\hline 21 & S-90 & 14 & Male & ++ & - & Positive \\
\hline 22 & S-92 & 35 & Female & +++ & +++ & Positive \\
\hline 23 & J-101 & 7 & Male & + & - & Positive \\
\hline 24 & $\mathrm{~J}-102$ & 15 & Female & + & - & Positive \\
\hline 25 & $\mathrm{~J}-103$ & 5 & Male & +++ & +++ & Positive \\
\hline 26 & J-104 & 25 & Female & ++ & - & Positive \\
\hline 27 & $\mathrm{~J}-105$ & 14 & Male & +++ & +++ & Positive \\
\hline 28 & $\mathrm{~J}-108$ & 20 & Male & +++ & +++ & Positive \\
\hline 29 & $\mathrm{~J}-115$ & 30 & Female & +++ & +++ & Positive \\
\hline \multicolumn{4}{|c|}{ Total } & $\begin{array}{c}28 / 117 \\
(23.93 \%)\end{array}$ & $\begin{array}{c}18 / 117 \\
(15.38 \%)\end{array}$ & $\begin{array}{c}26 / 117 \\
(22.22 \%)\end{array}$ \\
\hline
\end{tabular}

Table.5 Rotavirus prevalence in various regions

\begin{tabular}{|c|c|c|c|}
\hline Regions & Total no. of sample & $\begin{array}{c}\text { No. of positive } \\
\text { samples }\end{array}$ & Prevalence \% \\
\hline Junagadh & 18 & 07 & 38.88 \\
\hline Anand & 31 & 07 & 22.58 \\
\hline Surat & 68 & 12 & 17.64 \\
\hline Total & $\mathbf{1 1 7}$ & $\mathbf{2 6}$ & $\mathbf{2 2 . 2 2}$ \\
\hline
\end{tabular}

Table.6 Rotavirus prevalence by RT-PCR in various age groups and sex

\begin{tabular}{|c|c|c|c|}
\hline Age groups(Days) & No. of positive samples & \multicolumn{2}{|c|}{ Sex wise Prevalence of Rotavirus } \\
\cline { 3 - 4 } & & $\begin{array}{c}\text { No. of male calves } \\
\text { Infected }\end{array}$ & $\begin{array}{c}\text { No. of female calves } \\
\text { infected }\end{array}$ \\
\hline I & $10(38.40 \%)$ & 6 & 4 \\
$(\mathbf{1 - 1 0})$ & & $(60 \%)$ & $(40 \%)$ \\
\hline II & $8(30.76 \%)$ & 6 & 2 \\
$(\mathbf{1 1 - 2 0})$ & & $(75 \%)$ & $(25 \%)$ \\
\hline III & $5(19.23 \%)$ & 1 & 4 \\
$(\mathbf{2 1 - 3 0})$ & & $(20 \%)$ & $(80 \%)$ \\
\hline IV & $3(11.53 \%)$ & $1(33.33 \%)$ & 2 \\
$(\mathbf{3 1 - 6 0})$ & & & $(66.66)$ \\
\hline Total & $\mathbf{2 6}$ & $\mathbf{1 4}$ & $\mathbf{1 2}$ \\
& & $\mathbf{5 3 . 8 5 \% )}$ & $\mathbf{( 4 6 . 1 5 \% )}$ \\
\hline
\end{tabular}


Fig.1Latex agglutination test kit

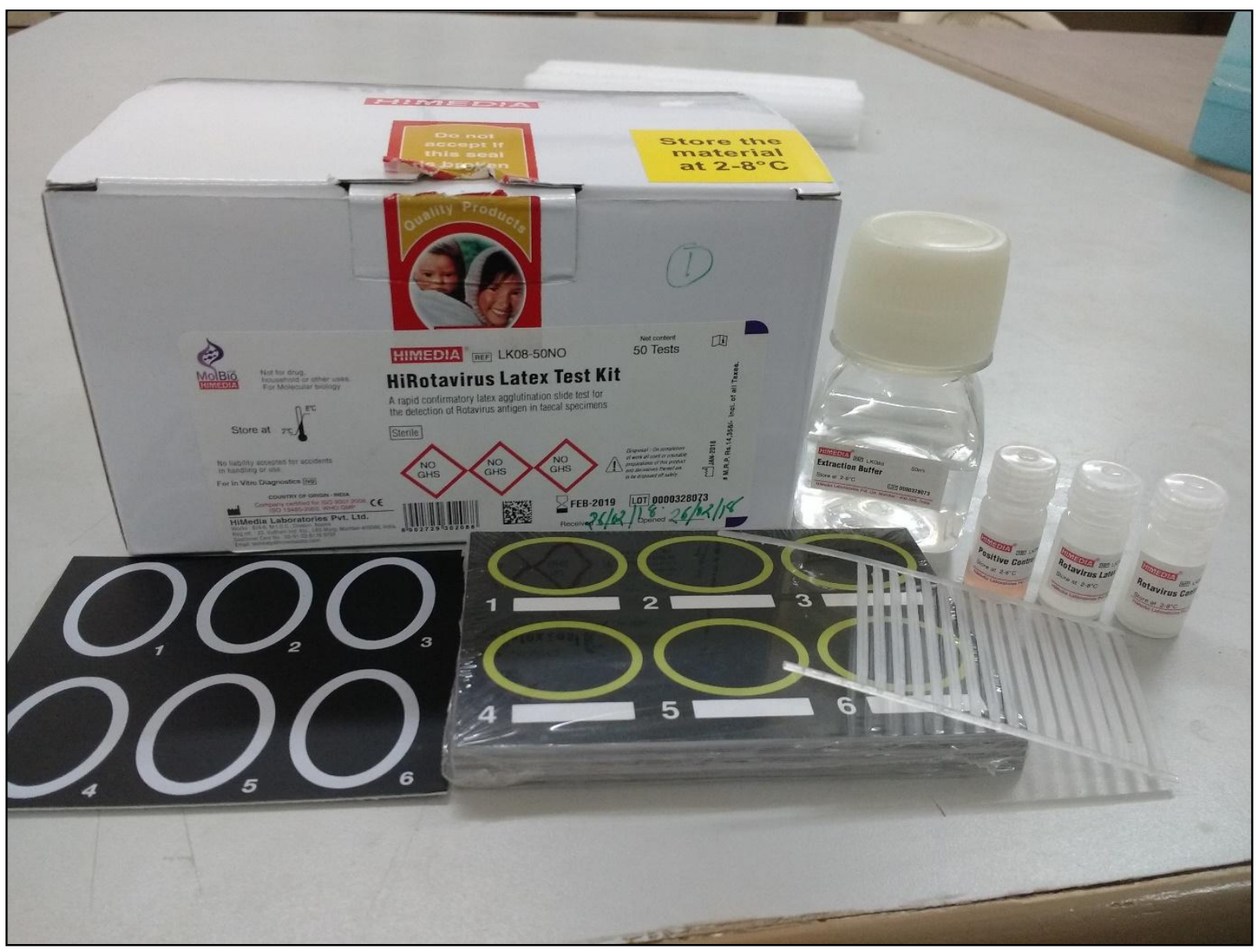

Fig.2 Components of Sandwich ELISA kit

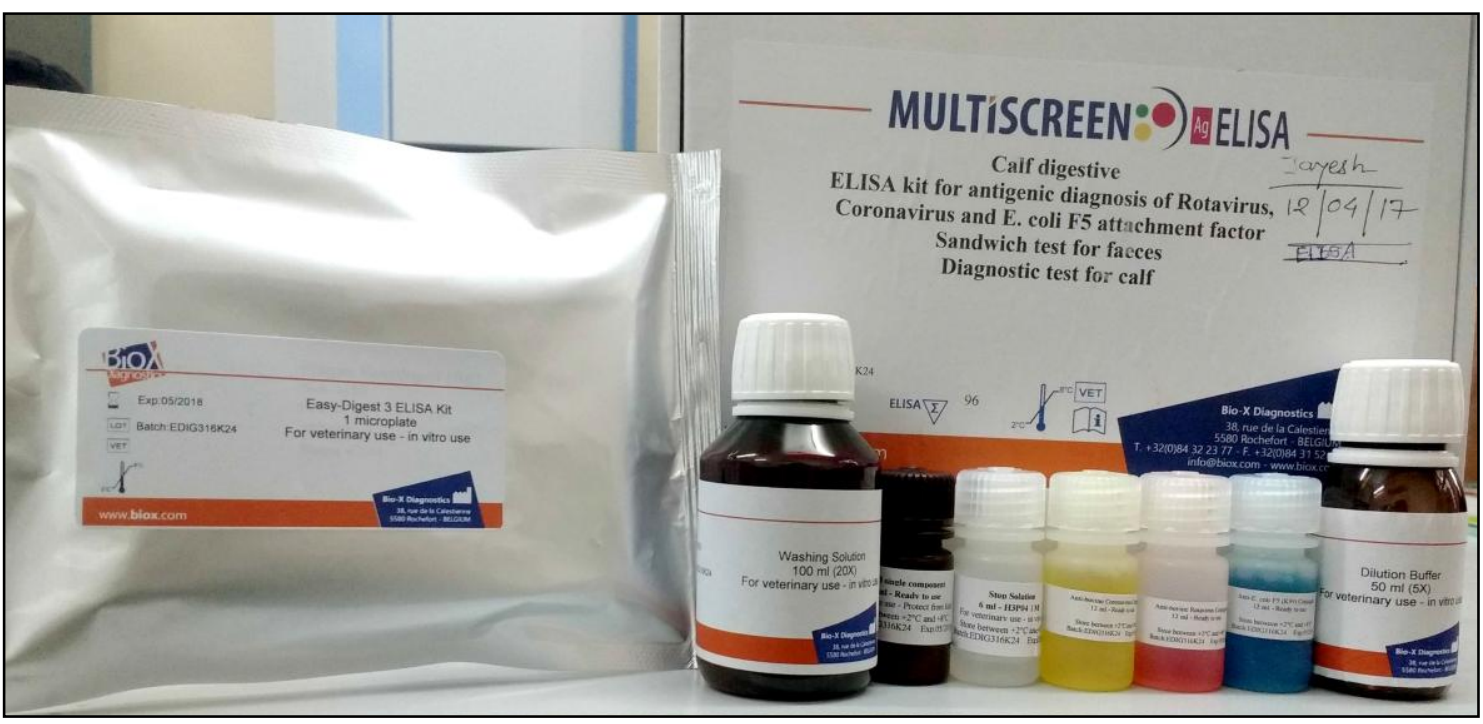


Fig.3 Agarose gel showing amplified product for VP6- gene ofRotavirus isolates (approximately 379bp)

L: DNA Molecular weight ladder - 1000bp,

1-4: Isolates (Samples)

P: Positive control

$\mathrm{N}$ : Negative control

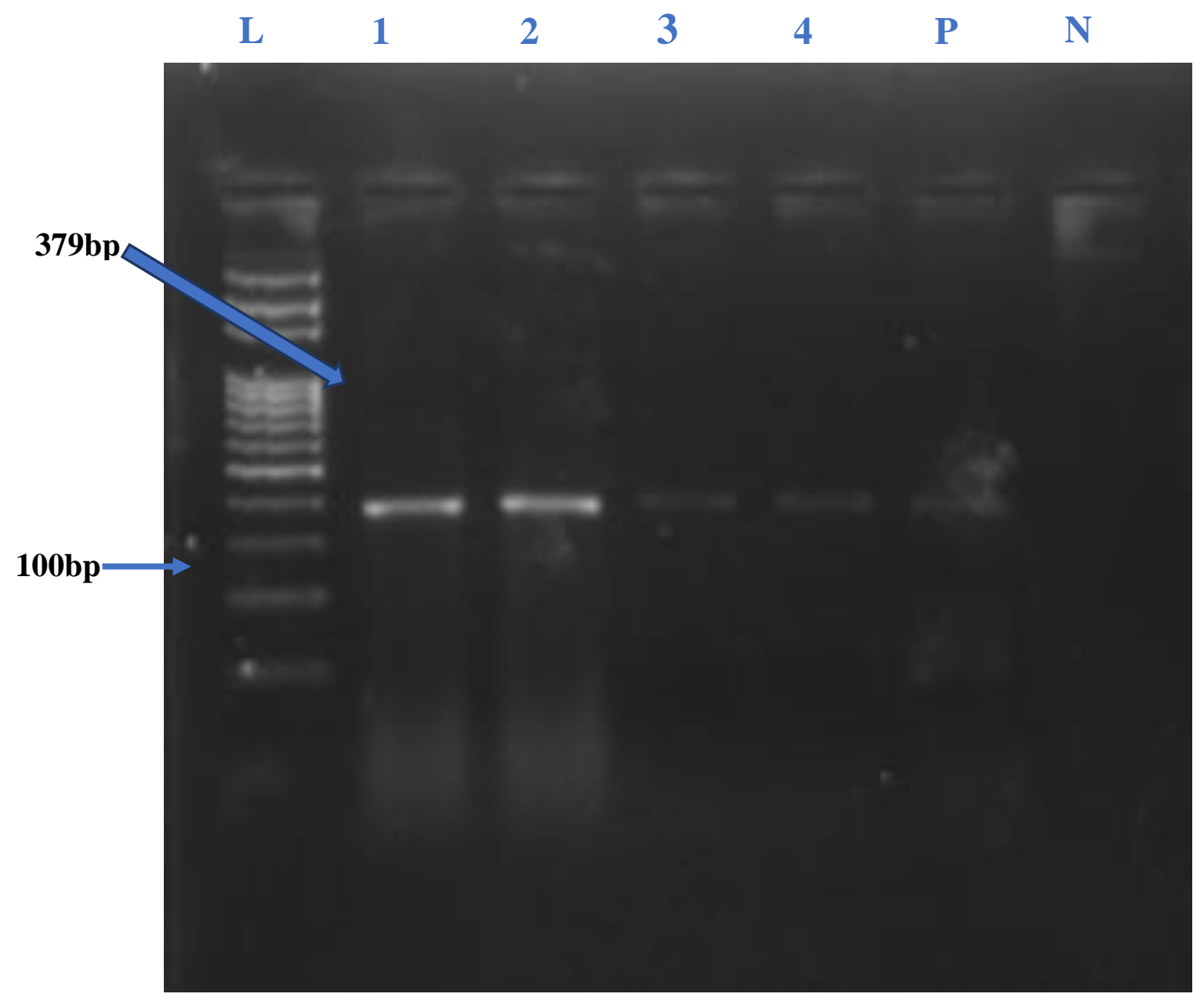


Fig. 4 Screening for Rotavirus using Latex Agglutination Test kit (1-4: Samples, 5:

Positive control, 6: Negative control

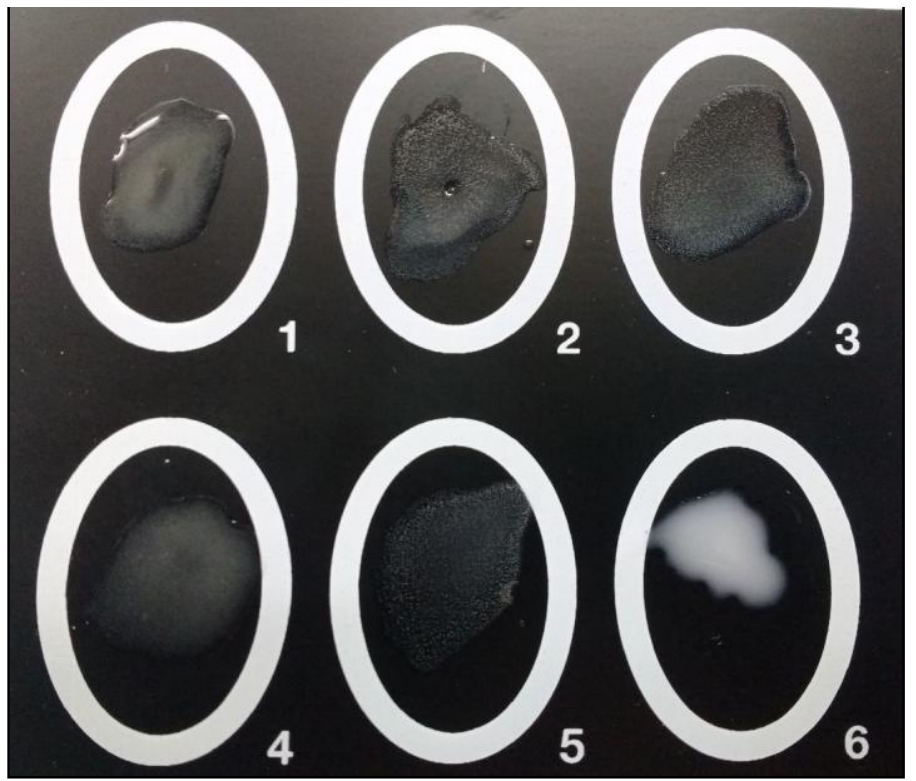

Fig.5 Screening for Rotavirus using Sandwich ELISA (C1-H9: Samples, A1: Positive control, B1: Negative control

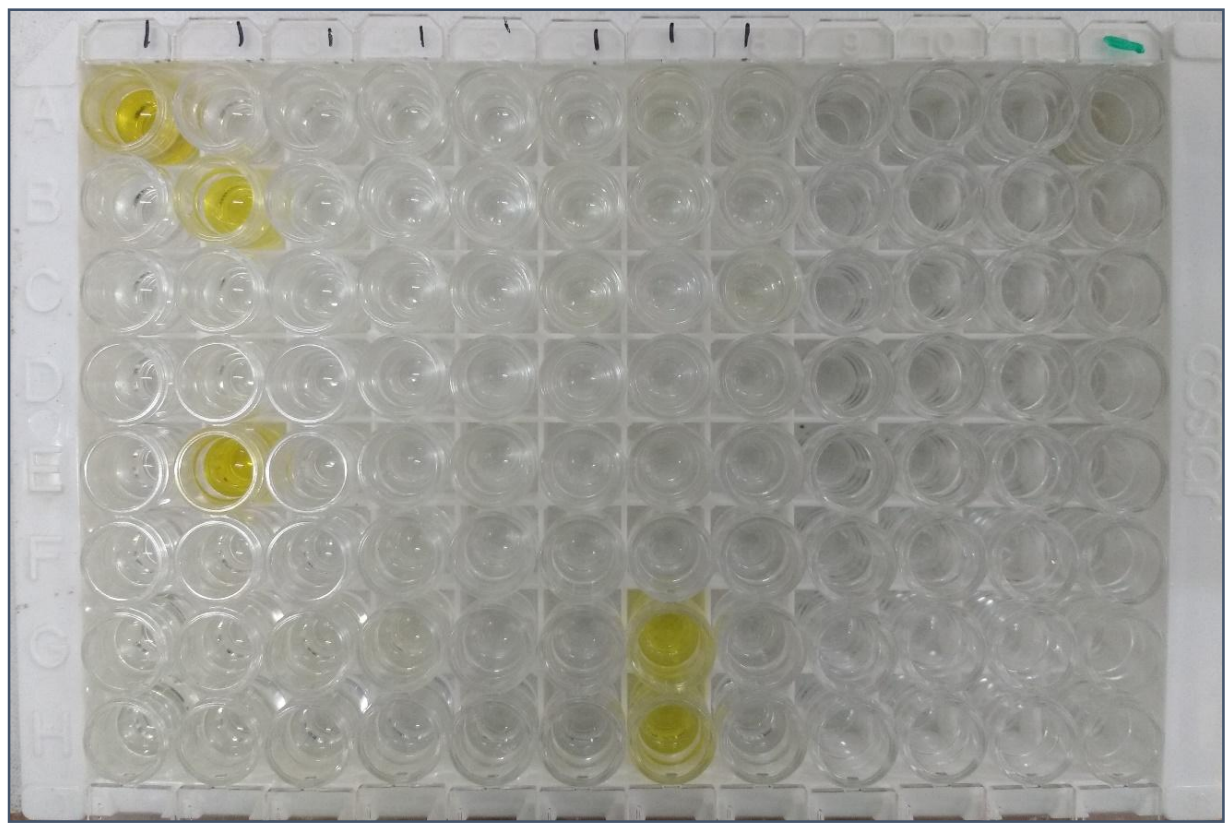

The prevalence of Rotavirus is higher in 1-10 days age group, this finding is supported by Ammar et al., (2014) and Khamees (2015) they also reported $(60.80 \%$ and $19.23 \%)$ and higher prevalence of Rotavirus infection in 110 days age group. A higher infection rate in the first week of life suggests widespread rotavirus in this group of younger calves reported by Selim et al., (1991) and Majeed et al., (2011). As numerous factors interplay in precipitating clinical diarrhoea, it is difficult to make absolute conclusions based on the limited information. However, rotavirus infection has been shown to be more 
important than other agents in diarrhoea in young calves of around 1 week of age (4-14 days) (Selim et al., 1991). In the present investigation, $22(18.80 \%)$ diarrheic calves were infected with both E. coli and Rotavirus.

The resultant of effectiveness of sex on infection rate in present study which slightly higher in male (53.84\%) than female (46.15\%) but not much difference similar finding to those of Dash et al., (2011) and Hassan et al., (2014), they recorded infection rate $(20.37 \%)$ in male and $(12.76 \%)$ in female and $37.5 \%$ in males and $40 \%$ in females, respectively. In contrast to the present study, Ammar et al., (2014) recorded higher frequency of infection of rotavirus in female $(60.86 \%)$ as compared to the male (39.13\%). The anatomical, functional and hormonal similarities of body systems of male and female calves in early ages lead to non-specific resistance against infection, but degree of contamination with virus, dose of viruses, exposing to stress factors, consumption of colostrum or not and other many environmental and management factors, all effect on infection rate and severity in both sexes of calves in same or different periodic age as reported by Hassan et al., (2014). Calves within their first month of life are highly susceptible to viral diarrhea probably due to suckling milk, which neutralizes the acidic $\mathrm{pH}$ of their digestive tract and in turn allows several pathogens to survive (Dhama et al., 2009: Cho and Yoon, 2014). Several improvements in vaccination, medication and management have been implemented to reduce the incidence of NCD. However, NCD is still persistent because it is complex and multifactorial and can be triggered by several different infectious and non-infectious causes (Cho and Yoon, 2014). Direct losses are due to dehydration, reduced growth rate, and high morbidity and mortality.

Indirect losses are due to the imposition of trade restrictions and increased costs of management and veterinary care as well as animal suffering.

\section{Comparison of LAT, ELISA and RT-PCR for Rotavirus detection}

In the present study, the difference in the results of nine samples was recorded for LAT and ELISA i.e. LAT showed nine samples positive for Rotavirus while the same samples were negative by ELISA. The LAT results (23.93\%) were almost similar to that of the RT-PCR $(22.22 \%)$. These results indicated that LAT was more sensitive than ELISA and thus, former technique should be used for screening of Rotavirus detection. However, two fecal samples were weak positive by LAT and negative by ELISA and RT-PCR. This variation in result of LAT and RT-PCR might be due to cross agglutination with another organism present in the fecal sample.

\section{Acknowledgement}

I would like to acknowledge my major guide Dr. R. A. Mathakiya, Assistant Professor, Dept. of Veterinary Microbiology, AAU, Anand and Veterinary College of Veterinary Science \& Animal Husbandry for their moral and financial support to my research work.

\section{References}

Abdulazeez, A. A., and Abed, M. N. 2017. Genotyping of Rotavirus in neonatal calves with acute gastroenteritis in Iraq. Advances in Microbiology, 7(12), 863.

Al-Robaiee, I. A., and Al-Farwachi, M. I. 2013. Prevalence of rotaviral infection in diarrheic neonatal calves in Mosul city, Iraq. Veterinary World, 6, 538540.

Al-Yousif, Y., Anderson, J., ChardBergstrom, C., Bustamante, A., Muenzenberger, M., Austin, K., and Kapil, S. 2001. Evaluation of a latex 
agglutination kit (VirogenRotatest) for detection of Bovine Rotavirus in fecal samples. Clinical and Diagnostic

Ammar, S. S. M., et al., 2014. Prevalence of Rotavirus (GARV) and Coronavirus (BCoV) associated with neonatal diarrhea in calves in western Algeria. Asian Pacific Journal of Tropical Biomedicine, 4, S318-S322.

Cho, Y. I., and Yoon, K. J. 2014. An overview of calf diarrhea-infectious etiology, diagnosis, and intervention. Journal of Veterinary Science, 15(1), 1-17.

Dash, S. K., Tewari, A., Kumar, K., Goel, A., and Bhatia, A. K. 2011. Detection of Rotavirus from diarrhoeic cow calves in Mathura, India. Veterinary World, 4(12), 554-556.

Dhama, K., Chauhan, R. S., Mahendran, M., and Malik, S. V. S. 2009. Rotavirus diarrhea in bovines and other domestic animals. Veterinary Research Communications, 33(1), 123.

Estes, M. K., and Kapikian, A. Z. 2007. Fields' Virology, 5th edition. Kluwer, Philadelphia, 1971-1974.

Flewett, T. H., Bryden, A. S., Davies, H., Woode, G. N., Bridger, J., and Derrick, J. 1974. Relation between viruses from acute gastroenteritis of children and newborn calves. The Lancet, 304(7872), 61-63.

genotype from diarrhoeic calves in northern and southern states of India. Veterinary

Gill, G. S., Kaur, S., Dwivedi, P. N., and Gill, J. P. S. 2017. Comparative prevalence and molecular characterization of group A Rotavirus in cow calves of Punjab, India. Journal of Animal Research, 7(5), 927-933.

Hasaan, H. A. H. Q. H., and Mansur, K. A. 2014. Detection of Bovine Rotavirus in diarrheic calves by using rapid test in some Mid-Euphrates provinces.

Khamees A. K. 2015. Detection of Rota- and Corona viral antigens in diarrheic newly born calves. Benha Veterinary

Medical Journal, 29(1), 9-16.

Laboratory Immunology, 8(3), 496-498.

Maclachlan, N. J., Dubovi, E. J., Barthold, S. W., Swayne, D. F., and Winton, J. R. 2016. Fenner's Veterinary Virology. 5th. Ed. Amsterdam, Boston, Elsevier/Ap. ISBN - 9780128009468.

Majeed, Q. A., Al-Batel, M. K., Abdou, N. E. M., El-Azazy, O. M., Sami, A. M., and El-Said, H. 2011. Infectious causes of neonatal diarrhea in cattle in Kuwait with special

Mebus, C. A., Underdahl, N. R., Rhodes, M. B., andTwiehaus, M. J. 1969. Calf diarrhea(scours): reproduced with a virus from a field outbreak. Research Bulletin, 233.

Methods, 189(1), 36-40.

Mondal, A., Sharma, K., Malik, Y. S., andJoardar, S. N. 2013. Detection of group A Rotavirus in faeces of diarrhoeic bovine porcine and human population from eastern India by reverse transcriptase-polymerase chain reaction. Population, 09-16.

Pardo-Mora, D., Vargas-Bermúdez, D. S., Oliver-Espinosa, O., and JaimeCorrea, J. 2018. Molecular characterization of Rotaviruses isolated from calves with bovine neonatal diarrhea (BND) in Colombia. Infection, 22(2), 99-104.

Practitioners, 13(1), 1-8.

reference to Cryptosporidiosis. Journal of Animal and Veterinary Advances, 10(17),

Sambrook, J. R., \& Russel, D. W. 2012. DW 2001. RNA: A Laboratory Manual.

Selim, S. A., Aziz, K. M. S., Sarker, A. J., and Rahman, H.1991. Rotavirus infection in calves in Bangladesh. Veterinary Research Communications, 15(4), 327333.

Singh, T. C., andJhala, M. K. 2011. Comparing relative sensitivity and 
specificity of LA and RNA-PAGE in detecting bovine rotaviruses. Buffalo BulleitnIbic, Kasetsart University, Po Box 1084 Bangkok 10903, Thailand, $30(1), 36$.

Singh, T., Singh, A. P., Malik, Y. P. S., and Prasad, M. 2015. G and P types of bovine group A Rotavirus in northern India. Indian Journal of Animal Research, 49(6).

Sukura, A., andNeuvonen, E. 1990. Latex test for rapid Rotavirus diagnosis in calves. Acta Veterinaria Scandinavica, 31(1), $1-4$.
Suresh, T., Rai, R. B., Dhama, K., Sawant, P. M., Kumar, D., and Bhatt, P. 2012. Determination of $G$ and $P$ type diversity of group A Rotaviruses and detection of a new

Wei, S., Gong, Z., Che, T., Guli, A., and Tian, F. 2013. Genotyping of calves' Rotavirus in China by reverse transcription polymerase chain reaction. Journal of Virological

Yilmaz, V. 2016. Investigation of Rotavirus Infection in Calves with Diarrhea in Northeast Turkey. Animal and Veterinary Science, 4, 1, 1-4.

\section{How to cite this article:}

Jayesh Patel, Rafiyuddin Mathakiya and Akash Golaviya 2019. Detection of Bovine Rotavirus from Diarrheic Bovine calves in Gujarat region. Int.J.Curr.Microbiol.App.Sci. 8(09): 12821293. doi: https://doi.org/10.20546/ijcmas.2019.809.147 